\title{
Prevalence Of Androgen Receptor Positivity In Triple Negative Breast Cancer
}

\author{
Martin P Jovita $\mathbf{M}^{*}$, Kalaichelvi Kannan and Kumar S Suresh
}

Medical Oncology, Rajiv Gandhi Govt General Hospital, Chennai, India

*Corresponding author: Martin P Jovita M, Department of Medical Oncology, Rajiv Gandhi Govt General Hospital, Chennai, India, E-mail: jovimartin4@gmail.com

Received date: January 29, 2018; Accepted date: February 23, 2018; Published date: March 05, 2018

Copyright: () 2018 Martin PJM, et al. This is an open-access article distributed under the terms of the Creative Commons Attribution License, which permits unrestricted use, distribution, and reproduction in any medium, provided the original author and source are credited.

\begin{abstract}
A unique subgroup of breast cancer, the Triple negative Breast carcinoma (TNBC) is on the rising trend. TNBC occurrence is around $15-20 \%$ of all breast cancers. Therefore this makes it an ideal target for therapeutic exploitation. TNBC is defined by the absence of a target, therefore, there is absence of a tailored targeted therapy, leaving its management depend on conventional cytotoxic regimens. The presence of AR in ER negative cases is $30 \%$, in TNBC the AR positivity is $<20 \%$ (some studies have even accounted that the overall AR positivity in Breast cancer is $60-70 \%$ ). This group of patients poses a major challenge to the physicians and patientsThe total breast cancer patients between the periods of October 2014 to February 2014 were 734 cases, 142 cases were triple negative breast cancer cases as demonstrated by the Immunohistochemistry. Androgen receptor was considered positive if $>10 \%$ of cells showed positivity in Immunohistochemistry. Androgen receptor is Negative amongst a majority of $88 \%$ of patients with $12 \%$ remaining AR Positive off which $8 \%$ is High, 3 Medium and 1 Low Positive. The $p$ value is 0.000 which is $<0.05$ hence the value is significant. The percentage of AR positivity in TNBC in this study concurs with the literature findings. This explains the importance of the same in TNBC as it seems to be an important avenue for therapeutic targeting because, this group of patients do not have much options for treatment. Further studies, with the use of androgen receptor blockade through drugs like Bicalutamide/Enzalutamide/ Abireterone in AR positive TNBC could be studied to know the survival improvement.
\end{abstract}

Keywords Androgen receptor; Triple negative breast cancer

\section{Introduction}

Breast cancer is one of the most common cancers in women posing a major public health problem worldwide. There were 1.7 million women with breast cancers in 2012, which accounts for about $23 \%$ of all female cancers and an additional 6.3 million women who are survivors of breast cancer within the last 5 years [1].

Triple Negative Breast cancer (TNBC) is defined as negative for ER, PgR and Her 2 neu (with the finding of $<1 \%$ of tumor cell nuclei immunoreactive in immunohistochemistry, in the presence of the evidence of the sample that can express ER, PgR or Her 2 neu respectively as positive intrinsic controls). TNBC occurrence is on the rising trend. This has been recognized as a unique subgroup of breast cancer. TNBC occurrence is around $15-20 \%$ of all breast cancers [2-5]. The presence of AR in ER negative cases is $30 \%$, in TNBC the AR positivity is $<20 \%$ [6-9] (some studies have even accounted that the overall AR positivity in Breast cancer is 60-70\%) [10]. The expression of AR positivity is inversely proportional to the clinical outcome in TNBC. Therefore this makes it an ideal target for therapeutic exploitation. This study is to find out the percentage of AR positive TNBC patients in our population as it is a small group in the overall breast cancer population.

The Luminal AR is a subgroup expressing androgen receptors. By demonstrating $\mathrm{AR}$ positivity in breast cancer it is a prognostic and predictive factor [11-13]. AR +ve, TNBC are lower grade tumours showing good response to Neoadjuvant chemotherapy in locally advance breast cancer (LABC). Therapeutic targeted agents such as Bicalutamide, an anti-androgen can be used against $A R$ in $A R$ expressing TNBC. The AR positivity may reflect the natural history of the tumor (prognostic factor) and the likely response to treatment (predictive factor) added to this can be used as a therapeutic target [6,7].

AR Positivity is a potential target for TNBC but only accounts to $<20 \%$ of TNBC [6-9].

\section{Methods}

The total breast cancer patients between the period of October 2014 to February 2015 were 734 cases, 142 cases were triple negative breast cancer cases as demonstrated by the Immunohistochemistry. Through the Immmunohistochemistry method using Dako reagents, the presence of androgen receptor in the above group of 142 patients were studied.

For performance of the IHC staining for AR, antigen retrieval was performed as follows: five micron sections are deparaffinized and rehydrated to deionized water. They are heated in citrate buffer $(\mathrm{pH}$ 6.0) using an electric pressure cooker for three minutes at 12-15 pounds per square inch (PSI) at approximately 120 degrees Celsius. They are then cooled for ten minutes prior to Immunostaining.

All slides were loaded onto an automated system (DAKO Autostainer plus, DAKO) and exposed to 3\% hydrogen peroxide for 5 minutes, incubated with primary antibody for thirty minutes, with labeled polymer for thirty minutes, 3,3'-diaminobenzidine (DAB) as chromogen for five minutes, and then with hematoxylin as counterstain for five minutes.

These incubations are performed at room temperature; between incubations sections are washed with Tris-buffered saline (TBS). 
Page 2 of 6

Coverslipping was performed using the Tissue-Tek SCA (Sakura Finetek) Coverslipper. Positive controls of known positive tissues (prostate cancer) and negative controls with primary antibody replaced with TBS were run with the patient slides. Samples were scored positive for AR when at least $10 \%$ of the nuclei of tumor cells were immmunoreactive. Further positivity of AR were catogorised as low positive $(<10 \%$ of the nuclei of tumor cells were immmunoreactive), medium positive (about $10 \%$ of the nuclei of tumor cells were immmunoreactive) and high positive $(>10 \%$ of the nuclei of tumor cells were immmunoreactive) (Figures 1 and 2) [14].

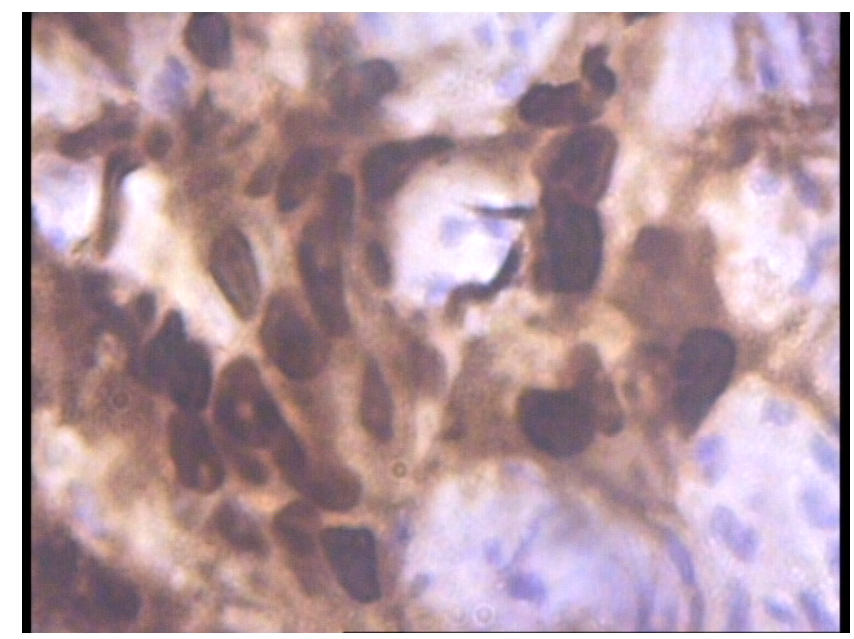

Figure 1: AR Positive in high magnification.

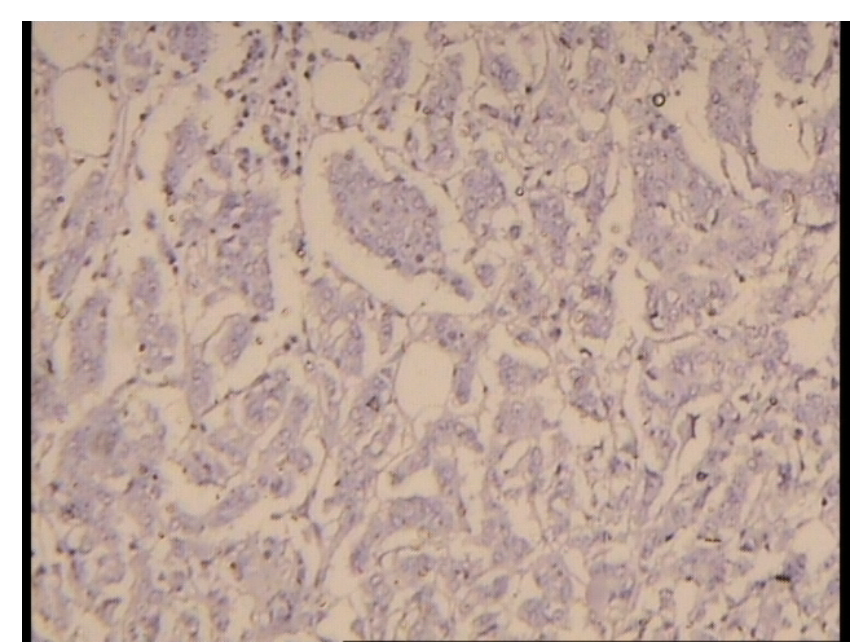

Figure 2: AR Negative.

\section{Results}

The results obtained were recorded in an Excel format. AR presence was demonstrated in TNBC correlated with the pathological parameters and results were analyzed by using non-parametric Chi square tests with the help of Graphpad Instat Version 3.1 and the SPSS version 22 statistical software. A 'p' value of $<0.05$ was considered significant.

\section{Statistics}

Continuous data are expressed as mean \pm standard deviation (SD) and categorical data as frequency counts (percentages). Baseline characteristics of patients were compared among TNBC with or without AR receptor positivity ones by non-parametric Chi squared tests. AR receptor positivity was compared for each categorical baseline variable. Univariable analysis by the use of the Chi square test were performed to assess the influence of $\mathrm{AR}$ receptor and of established clinical and histopathological parameters. A 'p' value of less than 0.05 was considered to indicate the statistical significance. All analyses were performed using Graphpad Instat Version 3.1 and IBM SPSS Statistics V22.0.0.

In the review of literature the premenopausal status has been associated with increased incidence of triple-negative breast cancer $[15,16]$. Negative AR is found in Pre, Post and Peri Menopausal stages. A High Positive AR is also found in all stages of Menopause. Moderately positive AR is found only in Pre and Peri Menopausal stage while Low Positive AR is found only in Post and Peri Menopausal stage cases. Triple-negative breast cancer is usually of high grade [17]. The studies show $84 \%$ of TNBC in grade III [4,5]. In this study both Positive and Negative AR is found in all irrespective of the Grades with the only exception of Moderately positive AR being found in Grade 2 and grade 3 cases only (Figure 3 ).

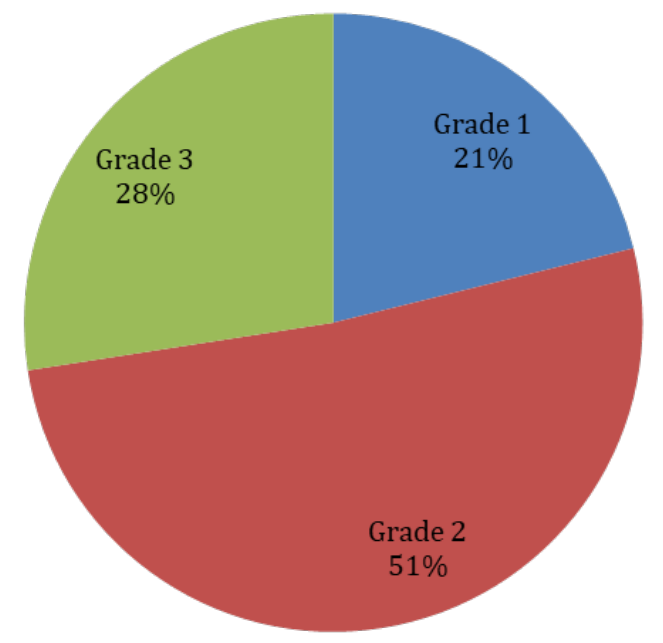

Figure 3: Invasive Breast Cancer Grades.

Studies also show most TNBC tumors were $>2 \mathrm{~cm}[4,5]$. In this study AR is found highly positive in Cancer Stages IIA and above. It remains negative in Stages IA and IB. Moderately positive AR is found in Cancer Stages IIIB and IV only. Low Positive AR is found in Stages IB, IIA, IIIB and IIIC only (Figure 4). 


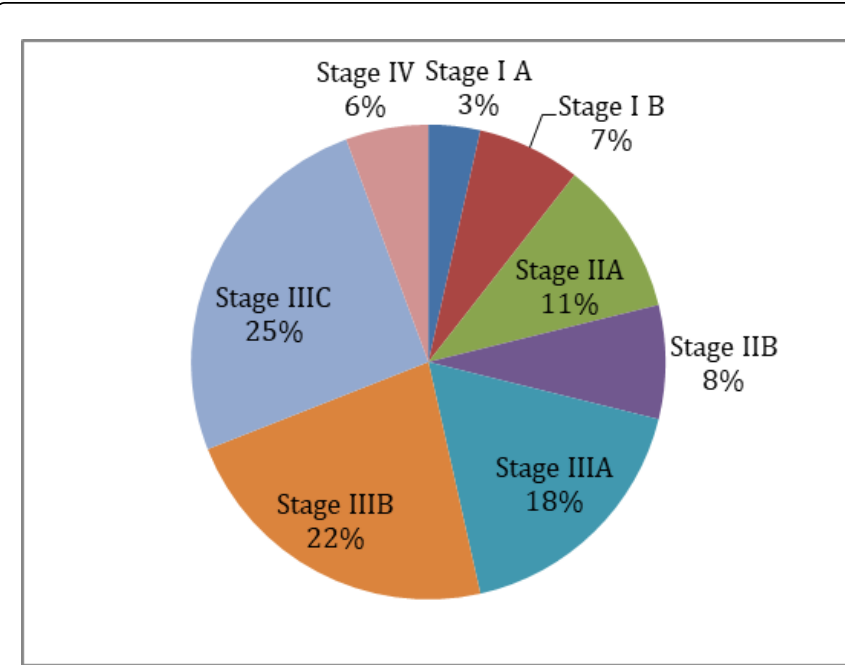

Figure 4: AR positivity in different stages.

The literature review shows $40 \%$ are positive for axillary lymph node. In this study $<3 \mathrm{LN}$ had maximum AR positivity of $6.9 \%$ out of $58.3 \%, 4-9 \mathrm{LN}$ the AR was positive in $4.2 \%$ out of $18.1 \%$ and $>9 \mathrm{LN}$ $1.4 \%$ was positive for AR out of $11.1 \%$. Therefore it can be said that nodal positivity of lower numbers has more chance of AR positivity. The presence of AR in ER negative cases is $30 \%$, in TNBC the AR positivity is $<20 \%[3,6-9]$. The androgen receptor positivity percentage of this set of triple negative patients was compared with the data in the literature. Androgen receptor was considered positive if $>10 \%$ of cells showed positivity in Immunohistochemistry. Androgen receptor positivity was further graded as low, medium and high positivity. Androgen receptor is Negative amongst a majority of $88 \%$ of patients with $12 \%$ remaining AR Positive off which $8 \%$ is High, 3 Medium and 1 Low Positive. The $p$ value is 0.000 which is $<0.05$ hence the value is significant. This explains the significance of AR positivity in TNBC as it seems to be an important avenue for therapeutic targeting because, this group of patients do not have much options for treatment (Figure $5)$.

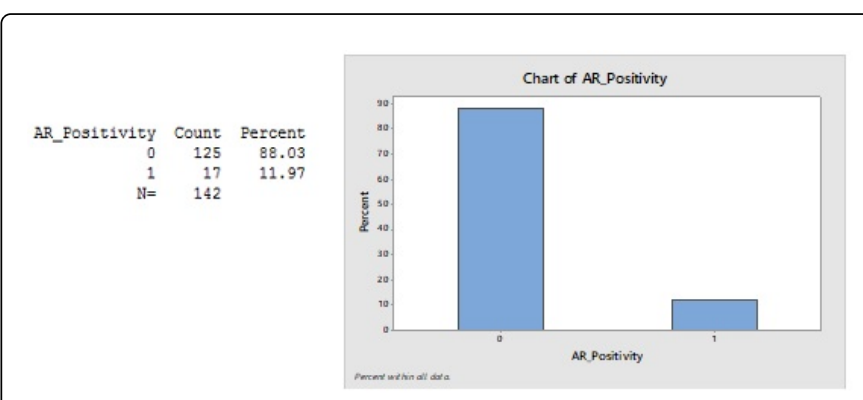

Figure 5: Androgen Receptor Graph 1.

Further studies, with the use of androgen receptor blockade through drugs like Bicalutamide in AR positive TNBC could be studied to know the survival improvement. AR is Negative amongst a majority of $88 \%$ of patients with $12 \%$ remaining AR Positive off which $8 \%$ is High, 3 Medium and 1 Low Positive (Graph 1, Figure 6, Table 1).

\begin{tabular}{|c|c|c|c|}
\hline \multicolumn{4}{|c|}{ Figure 6: Degree of AR positivity. } \\
\hline & \multicolumn{3}{|c|}{ Menopausal Stages } \\
\hline Androgen Receptor & Pre & Post & Peri \\
\hline High Positive & 2 & 7 & 2 \\
\hline Medium Positive & 1 & 0 & 1 \\
\hline Low Positive & 0 & 3 & 1 \\
\hline Negative & 40 & 61 & 24 \\
\hline
\end{tabular}

Table 1: AR positivity in correlation with Menopausal status.

\section{Discussion}

Breast cancer cases with ER positivity is about $70 \%$, HER 2 neu positivity is about $15 \%$ and TNBC is about $15 \%[4,5]$. The occurrence of AR in TNBC has recently drawn attention recently. One third of ER negative cases and one third of BRCA positive cases with high grade invasive cancers have AR expression [18,19].

Androgens are necessary precursors of Estrogen synthesis in the ovary. Androgens are secreted by both ovaries and adrenals. The main Androgen is secreted as Androgen dehydro epiandrosterone sulfate and non sulphated forms (DHEAS or DHEA respectively) inhibits growth of breast cancer. Androstendione is the other precursor of testosterone converting the low potency to high potency form, expressed in many cell types such as stromal breast cancer cells and epithelial cells [20]. Studies have shown increased testosterone levels and low progesterone levels have increased risk for breast cáncer [21]. Low urine and serum levels of DHEAS or their metabolites are associated with increased of breast cancer in premenopausal women [22].

Studies have elaborated on the dual action of DHEA. In premenopausal women with a high estrogenic milieu, the DHEA acts as an estrogenic antagonist through the competitive binding of 5 androstene 3 beta 17 beta diol (ADIOL) to ER Beta. On the contrary in the postmenopausal women the same DHEA acts as estrogen agonist (Figure 7) [23]. 
Page 4 of 6

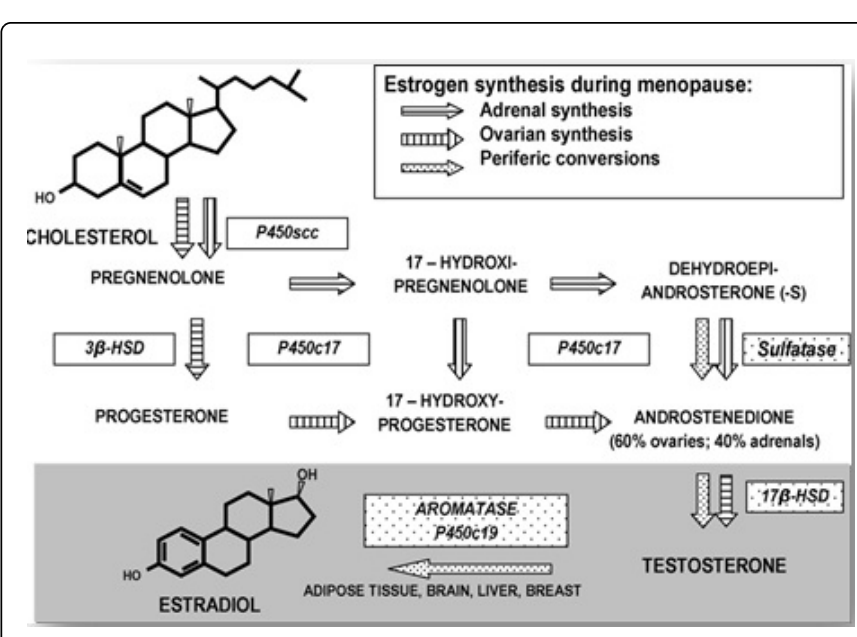

Figure 7: Estrogen synthesis during menopause.

There are three hypothesis for the risk of breast cancer.

- Ovarian Hyperandrogenism/ luteal inadequacy Hypothesis: The risk of breast cancer increases with excess ovarian androgens, chronic anovulation, reduction of luteal phase progesterone. There is direct increase in the serum androgen and the metabolites of androgen in serum and urine which has an impact on the breast tissue increasing cancer risk [22].

- Estrogen plus progesterone hypothesis: Increased levels of estrogen and progesterone causes increased proliferation during the luteal phase of menstrual cycle [24].

- Estrogen alone hypothesis: The increased levels of estrogen can promote breast tumor development and growth [25].

The dominant effect of androgens on estrogen-related tumours is antiproliferative and a decrease in AR-mediated effects might favour tumorigenesis $[26,27]$. The AR expression in ER + tumors confers good prognosis so also in ER- tumors the blockage of AR through targeted agents like Bicalutamide seems to be a potential therapeutic strategy, Phase II trial (NCT00468715).

Hence AR is a potential target for breast cancer [28]. AR expression correlates with better prognosis for both primary and metastatic cancer.

\section{ER negative subtypes}

The ER negative group of breast cancers consists of multiple subtypes (6 subtypes) [29,30]. Hence these tumors are ER negative, PR negative and HER2 negative on clinical assays. So they are nick named 'triple negative tumors. Most triple - negative breast cancers are basal - like whereas most basal - like tumors are triple negative [31]. The microarray defined six subgroups of TNBC are

- Basal-like 1

- Basal-like 2

- Immunomodulatory

- Mesenchymal-like

- Mesenchymal stem-like

- Luminal AR
Breakdown of TNBC by Microarray Defined Subtypes as Assigned by PAM (Figure 8 ).

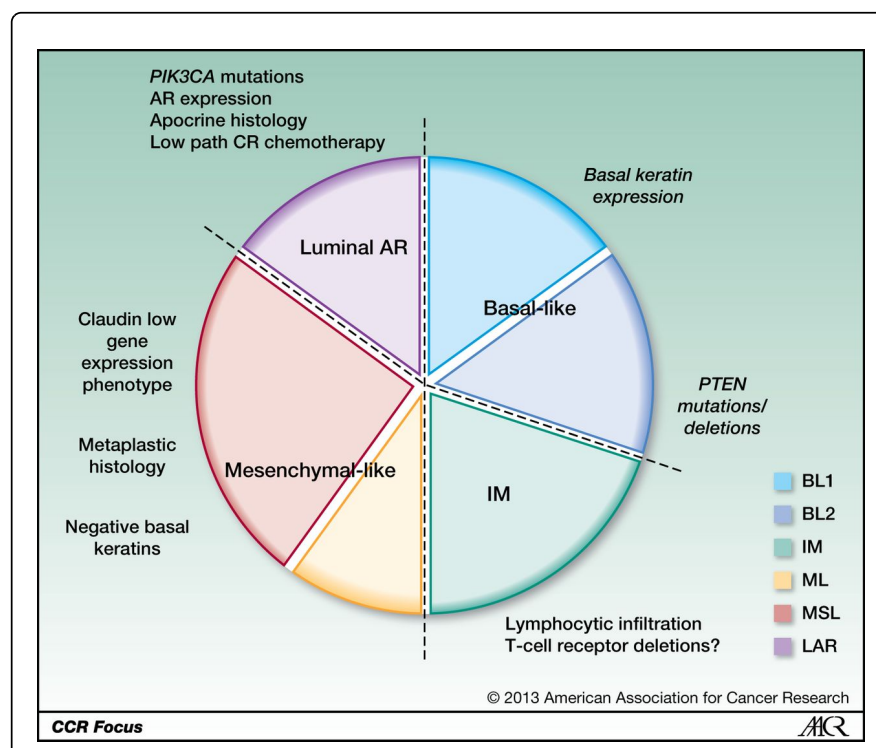

Figure 8: Molecular types in TNBC.

TNBC is defined by the absence of a target, therefore, there is absence of a tailored targeted therapy, leaving its management depend on conventional cytotoxic regimens (Table 2). This group of patients poses a major challenge to the physicians and patients. Hence, there is increasing research on this group of patients. Often TNBC is the proxy term used interchangeably with basal like breast cancer.

\begin{tabular}{|l|}
\hline Chemotherapy Anthracyclines, Taxanes, Microtubule Inhibitors, Antimetabolites, \\
Platins based in BRCA positive [33-35,38] \\
\hline Ixapapilone, Erubulin \\
\hline Motesanib \\
\hline Aflibercept \\
\hline IMC-18F1 \\
\hline HuMV833 \\
\hline Ramucirumab \\
\hline AMG 386 \\
\hline Pazopanib \\
\hline Cabozantinib \\
\hline Foretinib \\
\hline Tivozanib \\
\hline Sunitinib \\
\hline Sorafenib \\
\hline Vandetanib \\
\hline Vatalanib \\
\hline Axitinib \\
\hline
\end{tabular}


Page 5 of 6

\begin{tabular}{|l|}
\hline Semaximab \\
\hline Cediranib \\
\hline PARP inhibitors \\
\hline Iniparib (BSI-201) \\
\hline Olaparib (AZD-2281) \\
\hline EGFR inhibitors Cetuximab \\
\hline Veliparib (ABT-888) \\
\hline PF-01367338 \\
\hline mTOR inhibitors \\
\hline o Temsirolimus \\
\hline o Everolimus \\
\hline Cediranib \\
\hline MetMAb \\
\hline Antiangiogenic monoclonal inhibitors: Bevacizumab \\
\hline
\end{tabular}

Beta Blocker Use and Survival in TNBC Originally published by the American Society of Clinical Oncology.

Met inhibitor: ARQ197, onartuzumab (Metmab), foretinib

PI3K and/or inhibitor: BKM 120, temsirolimus (+ neratinib)

HDAC inhibitors: entinostat, vorinosat

Demethylatingagents:azacytidine (+ entinostat)

PARP inhibitors: ABT-888, E7449

Angiogenesis inhibitor: cediranib

(+ olaparib), ramicurumab, IMC18F1, foretenib, sorafenib

Hsp90 inhibitors: ganetespib

Aurora kinase inhibitors: ENMD 2076

EGF inhibitors: erlotinib (+ metformin),lapatanib

MEK inhibitors: GSK1120212

Wnt inhibitor: LGK974

CDK inhibitor: dinaciclib, P276-00

FMS-Kit inhibitor: PLX3397

Apoptosis inducer: LCL161 (deactivating inhibitor of apoptosis proteins)

Immunotherapy: MUC1 vaccine, adoptive cellular therapy (DC-CIK)

Cytotoxics: SN38 -NK012, AEZS-108 (LHRH-dox)

Death receptor targeting

Androgen receptor targeting

Table 2: Chemotherapy and targeted agents in TNBC.

The initial pilot study was done to demonstrate AR positive cases in TNBC with 72 patients, where we found $12 \%$ of cases were AR positive. The extension of the study to 142 patients was not only to check the AR positivity but also to do correlate with other variables. The Correlation of Androgen receptor positivity in TNBC with clinical parameters such as age, histo-pathological parameters, hormone receptor status and nodal status were analyzed in the breast cancer population reported to us. The very reason for this study is to find out which group of this heterogeneous TNBC would benefit with an alternative agent specific for its group as we know that TNBC is known for its aggressive behavior on recurrence with very little on our platter to offer the patient in a relapsed setting. The next step of the study is to prognosticate this subset of patients and possible enroll them in a trial using antiandrogens such as Bicalutamide/Enzalutamide/ Abiretrone acetate. However as our center is a tertiary care center with patients flocking from various villages. Hence the challenge we might face is that not all patients would continue treatment and follow-up in our center but might opt to do the same in their home town. This would make our follow up study and trial with antiandrogens on the AR positive TNBC patients rather difficult [32-40].

\section{Conclusion}

In this study, the Androgen receptor positivity was seen in perimenopausal, and postmenopausal age groups. The occurrence is equally spread out in all grades of tumor but more in Grade II and III. AR positivity was seen more in locally advanced breast cancer. AR positivity was seen more in cases with $<3 \mathrm{LN}$. There was no correlation between LVI. All cases in this study received chemotherapy. The percentage of AR positivity in TNBC in this study concurs with the literature findings. Hence more studies on AR positive cases in TNBC are warranted in order that the therapeutic exploitation might render us augmented clinical benefit for this subgroup of patients.

\section{References}

1. Parkin M, Bray F, Ferlay J, Pisani P (2005) Global cancer statistics, 2002. CA Cancer J Clin 55: 74-108.

2. Bertucci F, Finetti P, Birnbaum D (2012) Basal Breast Cancer: A Complex and Deadly Molecular Subtype. Curr Mol Med 12: 96-110.

3. Park S, Koo J, Park HS, Kim JH, Choi SY (2010) Expression or androgen receptors is primary breast cancer. Ann Oncol 21: 488-492.

4. Lachapelle J, Foulkes WD (2011) Triple negative and basal like breast cancer implications for Oncologists. Curr Oncol 18: 161-164.

5. Hanley K, Wang J, Bourne P, Yang Q, Gao AC, et al. (2008) Lack of expression of AR may play a critical role in transformation from in situ to invasive basal subtype of high grade ductal carcinoma of breast. Hum Pathol 39: 386-92.

6. Park S, Koo JS, Kim MS, Park HS, Lee JS, et al. (2011) Androgen receptor expression is significantly associated with better outcomes in estrogen receptor-positive breast cancers. Annals of Oncology 22: 1755-1762.

7. Bryan RM, Mercer RJ, Bennett RC, Rennie GC, Lie TH, et al. (1984) Androgen receptors in breast cancer. Cancer 54: 2436-2440.

8. Trivers KF, Lund MJ, Porter PL, LiffElaine JM, Flagg W, et al (2009) The epidemiology of triple-negative breast cancer, including race. Cancer Causes Control 20: 1071-1082.

9. Lin NU, Vanderplas A, Hughes ME, Theriault RL, Edge SB, et al. (2012) Clinicopathologic features, patterns of recurrence, and survival among women with triple-negative breast cancer in the National Comprehensive Cancer Network. Cancer 118: 5463-5472.

10. Hardin C, Pommier R, Calhoun K, Muller P, Jackson T, et al. (2007) A new harmonal therapy for estrogen receptor negative breast cancer. World J Surg 31: 1041-1046.

11. Mishra AK, Agrawal U, Negi S, Bansal A, MohilR, Chintamani C, et al. (2012) Expression of androgen receptor in breast cancer \& its correlation 
with other steroid receptors \& growth factors. Indian J Med Res 135 843-852.

12. Diaz-Chico BN, Rodriguez FG, Gonzalez A, Ramírez R, Bilbao C et al. (2007) Androgens and androgen receptors in breast cancer. Journal of Steroid Biochemistry \& Molecular Biology 105: 1-15.

13. Adamo B, Anders CK (2011) Stratifying triple-negative breast cancer: which definition(s) to use? Breast Cancer Research 13:105.

14. Hu R, Dawood S, Holmes MD, Collins LC, Schnitt SJ, et al. (2011) Androgen Receptor Expression and Breast cancer Survival in Postmenaupausal women. Clin Cancer Res 17: 1867-1874.

15. Millikan RC, Newman B, Tse CK, Moorman PG, Conway K, et al. (2008) Epidemiology of basal-like breast cancer. Breast Cancer Res Treat 109:123-139.

16. Carey LA, Perou CM, Livasy CA, Dressler LG, et al. (2006) Race, breast cancer subtypes, and survival in the Carolina Breast Cancer Study. JAMA 295:2492.

17. Livasy CA, Karaca G, Nanda R, et al (2006) Phenotypic evaluation of the basal-like subtype of invasive breast carcinoma. Mod Pathol 19:264

18. Hanley K, Wang J, Bourne P, Yang Q, Gao AC, et al. (2008) Lack of expression of AR may play a critical role in transformation from in situ to invasive basal subtype of high grade ductal carcinoma of breast. Hum Pathol 39: 386-392.

19. Pristauz G, Petru E, Stacher E, Geig JB, Schwarzbrau T, et al. (2010) Androgen receptor expression in breast cancer patients tested for BRCA 1and BRCA 2mutations. Histopathology 57: 877-884.

20. Secreto G, Toniolo P, Pisani P, Recchione C, Cavalleri A, et al. (1989) Androgens and breast cancer in premenopausal women. Cancer 49: 471-476.

21. Grattarola R (1964) The premenstrual endometrial pattern of women with breast cancer. A study of progestional activity. Cancer 17 : 1119-1122.

22. Page JH, Colditz GA, Rifai N, Barbieri RL, Willett WC, et al. (2004) Plasma adrenal androgens and risk of breast cancer in premenopausal woman, Cancer Epidemiol. Biomarkers Pre 13: 1032-1036.

23. Pike MC, Spicer DV, Dahmoush L, Press M (1993) Estrogens, progestogens, normal breast cell proliferation, and breast cancer risk. Epidemiology 15: 17-35.

24. Sixou SFD, Sergio CM, Carroll JS, Hui R, Musgrove EA, et al. (2003) Estrogen and antiestrogen regulation of cell cycle progression in breast cance cells, Endocr, relat. Cancer 10: 179-186.

25. Agoff SN, Swanson PE, Linden H, Hawes SE, Lawton TJ (2003) Androgen receptor expression in estrogen receptor-negative breast cancer. AmJ Clin Pathol 120: 725-731.

26. Prat A, Parker JS, Karginova O, Fan C, Livasy C, et al. (2010) Phenotypic and molecular characterization of the claudin-low intrinsic subtype of breast cancer. Breast Cancer Res 12:68.

27. Teschendorff AE, Miremadi A, Pinder SE, Ellis IO, Caldas C (2007) An immune response gene expression module identifies a good prognosis subtype in estrogen receptor negative breast cancer. Genome Biol 8: 157.
28. Perez EA, Patel T, Aspitia AM (2010) Efficacy of Ixabepilone in ER/PR/ HER2neu Triple negative breast cancer. Breast Cancer Res Treat 121: 261-271

29. Kaufman PA (2012) Eribulin Mesylate versus Capecitabine in Patients with Locally Advanced or Metastatic Breast Cancer Previously Treated with Anthracyclines and Taxanes SABCS Abstract S6-6.

30. Miller K, Wang M, Gralow J, Dickler M, Cobleigh M, et al. (2007) Paclitaxel plus bevacizumab versus paclitaxel alone for metastatic breast cancer. N Engl J Med 357: 2666-2676.

31. Rugo HS, et al (2012) Phase II study of weekly albumin-bound paclitaxel for patients with metastatic breast cancer ASCO. Abstract CRA1002.

32. Carey LA, Rugo HS, Marcom PK, Mayer EL, Esteva FJ, et al. (2012) TBCRC 001: Randomized Phase II Study of Cetuximab in Combination With Carboplatin in Stage IV Triple-Negative Breast Cancer J Clin Oncol 30: 2615-2623.

33. Brufsky A, Valero V, Tiangco B, Dakhil SR, Brize A, et al. (2011) Impact of bevacizumab (BEV) on efficacy of second-line chemotherapy (CT) for triple-negative breast cancer (TNBC): Analysis of RIBBON-2.Journal of Clinical Oncology 1010

34. Minckwitz GV, Untch M, Blohmer JU, Costa SD, Eidtmann H, et al. (2012) Definition and impact of pathologic complete response on prognosis after neoadjuvant chemotherapy in various intrinsic breast cancer subtypes. Journal of Clinical Oncology 30: 1796-1804.

35. Burstein HJ (2011) Bevacizumab for advanced breast cancer: all tied up with a RIBBON? J ClinOncol 29: 1232-1235.

36. Gucalp A, Tolaney S, Isakoff SJ, Ingle J, Liu MC, et al. (2012) Endocrine biomarkers in response to AR-inhibition with bicalutamide for the treatment of $\mathrm{AR}(+), \mathrm{ER} / \mathrm{PR}(-)$ metastatic breast cancer (MBC) (TBCRC011). Cancer Res 72 .

37. Shaughnessy JO, Osborne C, Pippen J, et al (2009) Efficacy of BSI-201, a poly (ADP-ribose) polymerase-1 (PARP1) inhibitor, in combination with gemcitabine/ carboplatin $(\mathrm{G} / \mathrm{C})$ in patients with metastatic triple-negative breast cancer (TNBC): results of a randomized phase II trial. J Clin Oncol 27 (18 Suppl): abstract 3.9

38. Shaughnessy JO, Osborne C, Pippen J, Yoffe M, Patt D, et al. (2011) Iniparib plus chemotherapy in metastatic triple-negative breast cancer. $\mathrm{N}$ Engl J Med 364: 205-214

39. Tutt A, Robson M, Garber JE, Domchek SM, Audeh MW, et al. (2010) Oral poly(ADP-ribose) polymerase inhibitor olaparib in patients with BRCA1 or BRCA2 mutations and advanced breast cancer: a proof-ofconcept trial. Lancet 376: 235-244.

40. Melhem BA, Chavez MM, Lei X, Brown EN, Lee RT, et al. (2011) Beta Blockers Use and Survival in TNBC Originally published by the American Society of Clinical Oncology. J ClinOncol 29: 2645-2652. 